\title{
Erratum
}

\section{To sell or not to sell: Overweight users' effect on fashion assortments}

Ulf Aagerup

Journal of Brand Management (2010) 18, 241. doi:10.1057/bm.2010.49

Correction to: Journal of Brand Management (2010) 18, 66-78. doi: 10.1057/bm.2010.23

The publisher would like to apologise that the acknowledgements section of the above article was incomplete and was published as follows:

I would like to thank Inger Larsson for her invaluable help. Her anthropometric data gave me the connection I needed between the population and the clothing sizes. I also owe a debt of gratitude to YYY and ZZZ, who helped me acquire the garment size data without which this study would have been impossible.

The correct acknowledgement is:

I would like to thank Inger Larsson for her invaluable help. Her anthropometric data gave me the connection I needed between the population and the clothes sizes. I also owe a debt of gratitude to Börje Nilsson and Alexander Holmén who helped me acquire the garment size data without which this study would be impossible. 